Research Article

\title{
Thermal and Residual Stress Distributions in Inconel 625 Butt-Welded Plates: Simulation and Experimental Validation
}

\author{
Harinadh Vemanaboina, ${ }^{1}$ Edison Gundabattini, ${ }^{2}$ Kaushik Kumar $\mathbb{D}^{3},{ }^{3}$ Paolo Ferro, ${ }^{4}$ \\ and B Sridhar Babu ${ }^{5}$ \\ ${ }^{1}$ Department of Mechanical Engineering, Sri Venkateswara College of Engineering and Technology (Autonomous), \\ Chittoor 517127, India \\ ${ }^{2}$ School of Mechanical Engineering, Vellore Institute of Technology, Vellore 632014, India \\ ${ }^{3}$ Deaprtment of Mechanical Engineering, Birla Institute of Technology Mesra, Ranchi, India \\ ${ }^{4}$ Department of Engineering and Management, University of Padova, Stradella S. Nicola 3, Vicenza 36100, Italy \\ ${ }^{5}$ Deaprtment of Mecanical Engineering, CMR Institute of Technology, Hyderabad, India
}

Correspondence should be addressed to Kaushik Kumar; kkumar@bitmesra.ac.in

Received 9 August 2021; Revised 13 September 2021; Accepted 23 September 2021; Published 19 October 2021

Academic Editor: Abílio De Jesus

Copyright (c) 2021 Harinadh Vemanaboina et al. This is an open access article distributed under the Creative Commons Attribution License, which permits unrestricted use, distribution, and reproduction in any medium, provided the original work is properly cited.

\begin{abstract}
Thermal and residual stress distributions induced by the gas tungsten arc welding (GTAW) process on Inconel 625 were studied using numerical simulation and experiments. A multi-pass welding model was developed that uses a volumetric heat source. Thermomechanical analysis is carried out to assess the Thermal and residual stress distributions. Experiments were carried out with $5 \mathrm{~mm}$ thick Inconel 625 plates. X-ray diffraction techniques were used to measure residual stresses, and IR thermometry was employed to capture the temperature values on the welded joints. Simulations were performed with ANSYS numerical code, and a close agreement was found between the predicted and experimentally measured residual stress. Thermal measurements were collected pass by pass from the analysis, and the agreement was $9.08 \%$. The agreement between the measured and analysed residual stress was $11 \%$.
\end{abstract}

\section{Introduction}

Fusion welding is one of the major joining techniques employed in industrial applications. In particular, gas tungsten arc welding (GTAW) allows yielding sound welds with different alloys. The selection of welding process parameters is one of the major challenging tasks to control welding residual stresses and distortions. Further, these welding process parameters will affect structural integrity. Experimental tests can be performed to estimate the improvement in parameters, but they are expensive and also quite time-consuming; in this scenario, welding numerical simulation may help avoid such drawbacks. Kermanpur et al. [1] developed an FEA model for multi-pass GTAW process of Incoloy 800 pipes. Temperature results obtained by using volumetric heat source were in good agreement with those obtained employing thermocouples located at the heat-affected zone of the joints. However, the authors did not focus on residual stresses caused by the joining process. In another recent work, Balram and Rajalakshmi [2] reported the experimental results regarding thermal stresses and thermal fields developed in the GTAW process applied to similar and dissimilar welded joints. The ERNiCrMo-3 alloy was used as filler wire. Tensile tests showed that the failure occurred within the parent metal, proving the high quality and strength of the welded joints obtained. Korrapati et al. [3] investigated the weldability and metallurgical and mechanical properties of the PCGTA welded Inconel 625 alloy employing ERNiCrMo-3 filler wire. In this case, despite the fact that defect-free welded joints were obtained, failures occurred at the weld region and the average tensile strength of the weldments was found to be $852.4 \mathrm{MPa}$. 
In order to decrease the computational time without losing accuracy, Perić et al. [4] proposed a T-joint numerical model conducted by combining the shell and 3D finite elements. Results of thermal and displacement distributions were found in good agreement with those measured in real joints. Finally, the influence of the 3D model size on the temperature, residual stress, and displacement distributions was investigated. Vemanaboina et al. [5] studied the residual stress evolutions in multi-pass dissimilar joints (IN 625-AISI 316L). The $L_{4}$ orthogonal array was chosen for the tests. Two levels of each welding factor, filler wire and root gap parameters, were chosen for the experiments. It was concluded that the pulsed current-induced low residual stresses in the weld region were within the factor of safety of parent materials. In subsequent work [6], they deepened the weldability of such similar and dissimilar welded joints. Weldments free from defects and stresses within the yield limits of the base materials were obtained. In computational weld mechanics (CWM) $[7,8]$, the thermal load is obtained by using power density distribution functions that calibrate parameters using experimental results. This approach allows reducing the computational time required to calculate the residual stresses and distortions compared to that needed by models based on fluid dynamic analyses.

Nine different welding sequences [9] were used to find the best conditions that minimized distortions and residual stresses in a T-weldment. The simulation was carried out by using ABAQUS numerical code. As expected, the best conditions were achieved when joining both sides in the same direction and at the same time. Kamble and Rao [10] developed a three-dimensional sequentially coupled thermomechanical model of $10 \mathrm{~mm}$ thick plate. The GMAW process was used for joining two $3 \mathrm{Cr} 12$ stainless steel plates. The thermal study was carried out at different time intervals. Thermally induced residual stress was predicted using ANSYS numerical code. In that work, the authors described the effect of process parameters on thermal and structural behaviour of the welded joints. Attarha and Sattari-Far described a thermal study of similar and dissimilar single-pass butt-welded joints [11]. A 3D numerical model was developed with ABAQUS ${ }^{\circledR}$, and the Goldak heat source was used to simulate the thermal input of the process (GTAW). Excellent agreement was observed between numerical and experimental temperature values measured with k-type thermocouples located in the heat-affected zone (HAZ). Capriccioli and Frosi [12] carried out a computational analysis of the multi-pass welding process for dissimilar materials. The $316 \mathrm{~L}$ stainless steel to IN625 welding simulation was carried out for both TIG and laser welding using ASNSYS $^{\circledR}$. The mechanical results were found very sensitive to the mesh shape, which had to be very fine and regular close to the fusion zones. In that work, an effort was made to reduce the CPU time that is the major objective to achieve when simulating a multi-pass welding process. Lostado et al. $[13,14]$ used finite element models to better understand heat behaviour and its impact on angular distortion and bead shape in GMAW butt weldments. The study employed genetic algorithms with multi-objective functions. The influence of heat input reveals growing angular distortion and weldment bead shape. The FEA models and experimental findings correlate well. Another work reported that the tensile residual is maximum at the fusion zone and also stated that the findings of the FEA were in agreement with the experimental results [15].

Weld beads and related regions undergo plastic deformation during the welding process as a result of heating and cooling cycles, resulting in residual stress. Thermal and lattice spacing impact residual stresses in weldments, resulting in microstructure changes and thermomechanical stresses. With the help of FEA, it is possible to forecast the degree of heat effect in the weldment. Since no work has been published on the in situ thermal behaviour study during GTAW for Inconel 625 material, the authors believe that there is a lack of confirmation on simulations for the estimate of temperature profiles and residual stresses. Multipass welding of Inconel 625 with GTAW process conditions is the major focus in the present planned study. Welded components are analysed in 3D to determine their thermal and residual stresses. With the ANSYS ${ }^{\circledR}$ package, APDL code is used to do thermomechanical analysis. Infrared thermography is used to measure welding temperatures. X-ray diffraction is used to evaluate residual stresses in a weldment after it has cooled to ambient temperature for verification.

\section{Finite Element Analysis}

Figure 1 shows an overview of the present numerical model. ANSYS package was used to develop the welding simulation. The plate has a square butt groove with no gaps between the two parts. According to the real butt-welded joint thickness, the FZ height was increased by $1.7 \mathrm{~mm}$ at each run, taking advantage of the activation-deactivation function of elements implemented in ANSYS code (Figure 2), roughly equal to that of weld bead measured by experiment. The thermal analysis was computed with the 8-node thermal element [16] SOLID70 and then switched to the 8-node finite element SOLID45 for the subsequent structural calculation. The two types of mesh options are used for the simulation models. The finer mesh is applied at fusion zone with a mesh size of $1.5 \mathrm{~mm}$, and coarse mesh is applied to the rest of the plate with a mesh size of $3 \mathrm{~mm}$, as shown in Figure 3. In this study, an equal time interval is assumed for every pass as heating time. The temperature-dependent [12] thermal and mechanical properties considered for Inconel 625 for the present study have been depicted in Figure 4 .

Goldak et al. proposed double ellipsoidal heat source model for the arc welding process [17]. For present weld simulations, the moving heat source model is treated as volumetric heat flux with constant heat input throughout the length. For each weld pass the bead size, initial boundary conditions are defined along with volumetric heat flux. The constant heat input loads are calculated as per the welding process parameters shown in Table 1 .

The volumetric heat flux $[18,19]$ of each weld pass is determined using the following equation:

$$
Q=\frac{\eta U I}{V}
$$




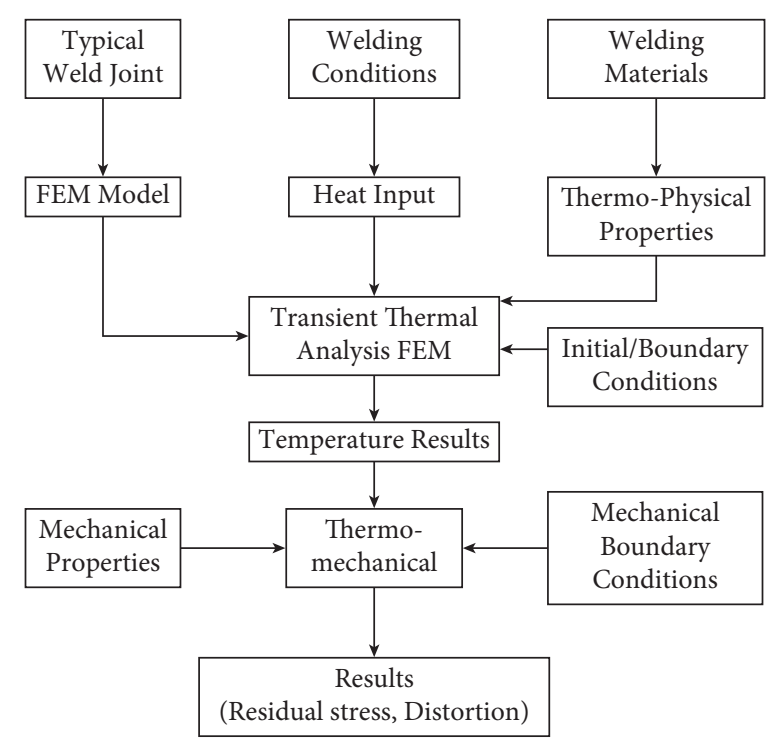

FIGURE 1: Overview of the thermo-elastic-plastic FEM analysis procedure.

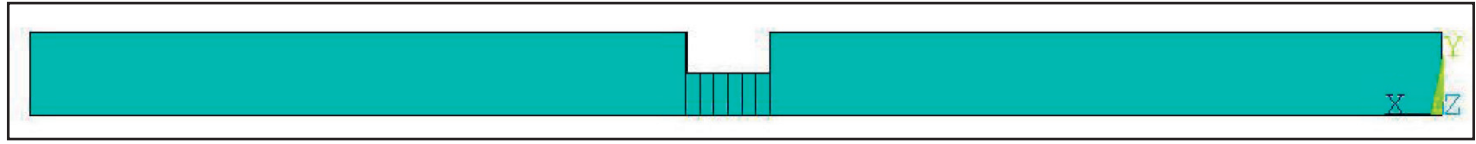

(a)

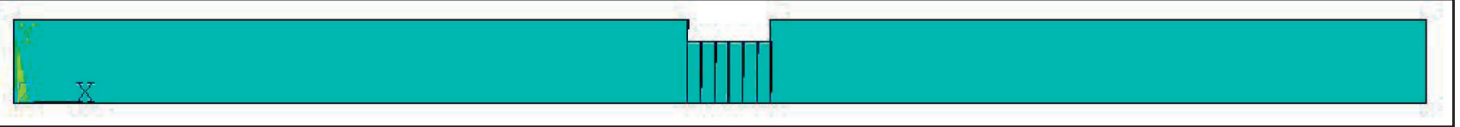

(b)

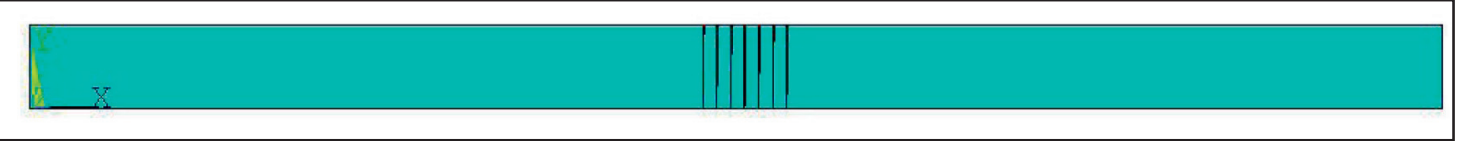

(c)

FIgURE 2: Simulation models for each pass. (a) Model for pass-1. (b) Model for pass-2. (c) Model for pass-3.

where $\eta$ is the arc welding efficiency, $U$ is the voltage, $I$ is the welding current, and $V$ is the volume of weld pass. The volume of the bead is added for each as shown in Figure 2. The value of arc efficiency is assumed to be 0.65 for the GTAW welding process. The heat conduction equation for welding simulation is given by

$$
\frac{\partial}{\partial x}\left(k \frac{\partial T}{\partial x}\right)+\frac{\partial}{\partial y}\left(k \frac{\partial T}{\partial y}\right)+\frac{\partial}{\partial z}\left(k \frac{\partial T}{\partial z}\right)+Q=-\rho C_{p} \frac{\partial T}{\partial t},
$$

where $\rho$ is the density, $C_{p}$ is the specific heat under constant pressure, and $k$ is the parent material conductivity. The coefficient of heat transfer rate was calculated for the weldment (equation (3)). Heat loss by convection was applied at the top and side faces of the weldment, while heat loss by both convection and radiation (equation (4)) was taken into account over the surface of the third weld bead obtained during the last welding run. In equations (4) and
(5), $T_{0}$ is the ambient temperature, $\varepsilon$ is the emissivity of the parent material, $\sigma$ is the Stefan-Boltzmann constant, and $h$ is the convective heat coefficient.

$$
\begin{aligned}
& H=24.1 * 10^{-4} \varepsilon T^{1.61}, \\
& q_{c}=h\left(T-T_{0}\right), \\
& q_{r}=\varepsilon \sigma\left(T^{4}-T_{0}^{4}\right) .
\end{aligned}
$$

Boundary conditions were applied in order to simulate the thermal behaviour induced by the three passes.

(1) For pass-1, initial temperature was ambient temperature.

(2) Convention was applied at the root opening of the plates for pass- 1 and pass- 2 .

(3) In pass-3, both convection and radiation were specified only on the top surface of the weld plate. 


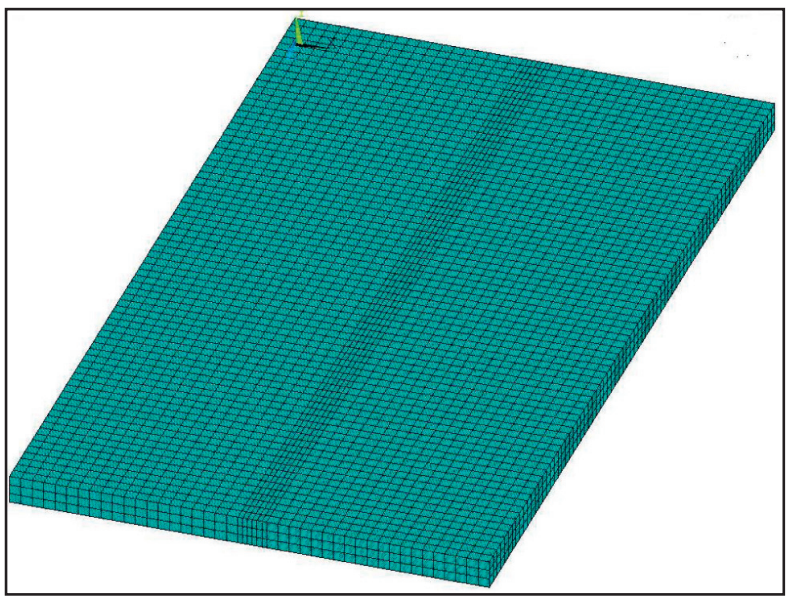

FIGURE 3: Meshing of the model.

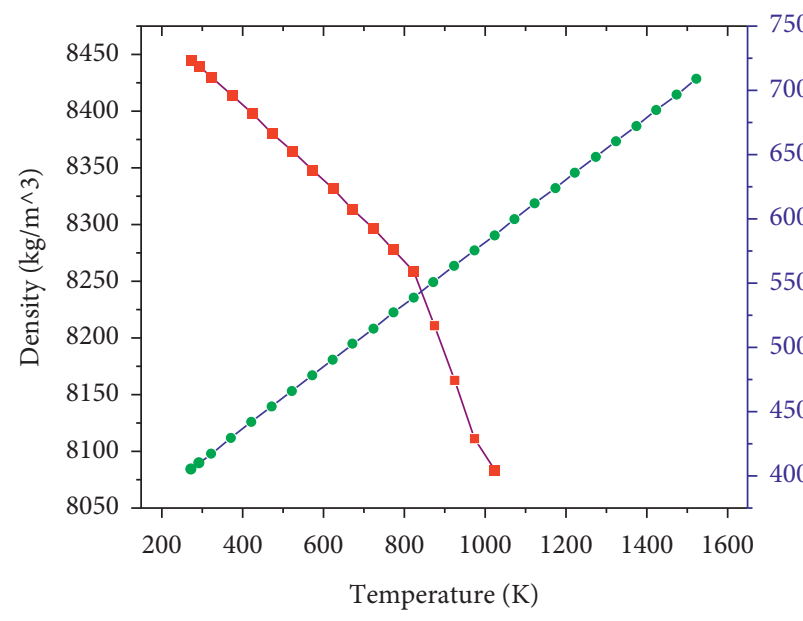

트 Density

-- Specific heat

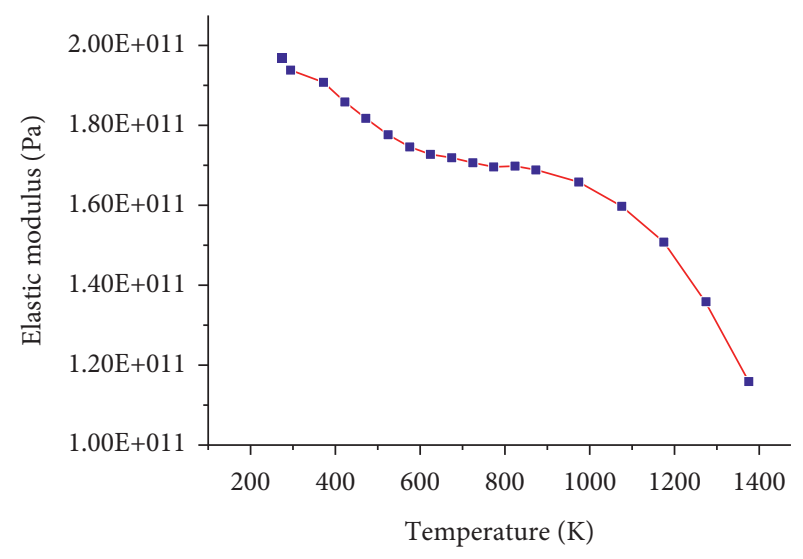

E- IN625

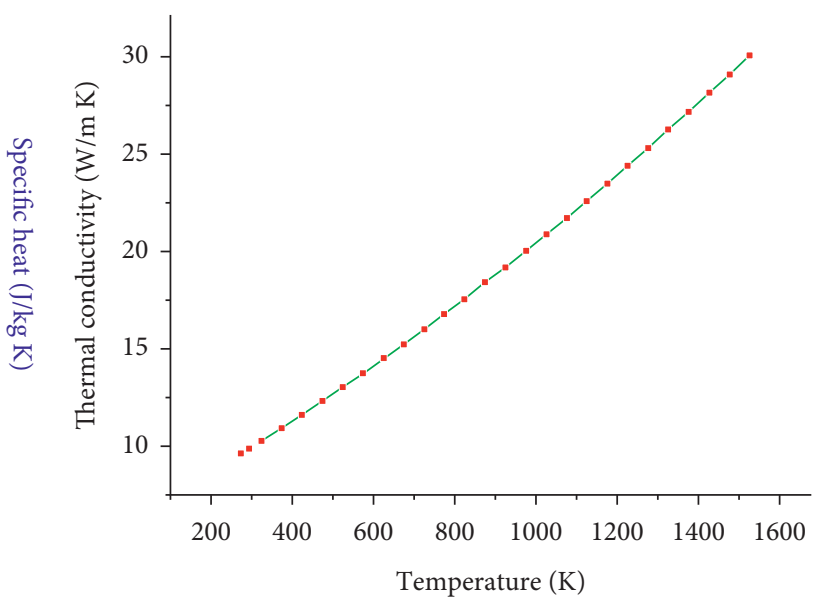

$\mp \square$ Thermal conductivity

(a)

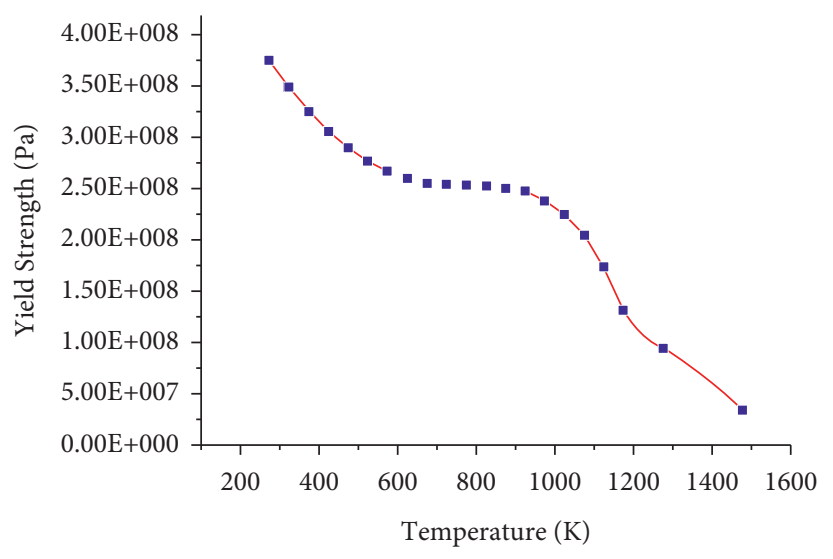

IN625

(b)

Figure 4: Temperature-dependent material properties. 
TABLE 1: Multi-pass welding process parameter.

\begin{tabular}{lcccc}
\hline Pass no. & $\begin{array}{c}\text { Welding current }(I) \\
\text { A }\end{array}$ & $\begin{array}{c}\text { Root gap } \\
\text { mm }\end{array}$ & $\begin{array}{c}\text { Argon gas flow rate } \\
\text { LPM }\end{array}$ & $\begin{array}{c}\text { Time for each pass } \\
\text { s }\end{array}$ \\
\hline Pass-1 & 145 & & & 36 \\
Pass-2 & 145 & 2 & & 27 \\
Pass-3 & 145 & & & 31 \\
\hline
\end{tabular}

(4) The inter-pass [20] temperature is considered for pass- 2 and pass- 3 to avoid hot cracking. The initial temperature for pass-I is ambient, i.e., $30^{\circ} \mathrm{C}$, and for pass- 2 and pass-3, it was maintained at about $200-250^{\circ} \mathrm{C}$

\section{Experimentation Procedure}

The real butt-welded joint was produced by the GTAW technique. The dimensions of the plates were $100 \mathrm{~mm}$ length $\times 60 \mathrm{~mm}$ width $\times 5 \mathrm{~mm}$ thickness, as shown in Figure 5. The single $\mathrm{V}$-groove angle of $60^{\circ}$ was used. The gap between the plates was filled with three passes: pass-1 (root pass), pass-2 (filler pass), and pass-3 (cap pass). ERNiCrMo3 was used as filler wire. Base material and filler wire chemical composition are given in Table 2 . The base material mechanical properties are listed in Table 3. The process parameters chosen for experimentation are welding current (I), root gap (RG), and shielding gas flow rate $(G)$ and are summarized in Table 1.

Welding current, root gap, and Argon flow rate were set to $145 \mathrm{~A}, 2 \mathrm{~mm}$, and 15LPM, respectively. The same parameters are used for all passes. To avoid the hot cracking in the weld, an inter-pass temperature [21] $\left(\sim 150-250^{\circ} \mathrm{C}\right)$ is maintained between the runs. Sound welded joints were obtained, and surface cracks and defects are verified by visual inspection and X-ray radiography.

\subsection{Measuring Techniques}

3.1.1. Infrared Thermography. Infrared thermography and $\mathrm{X}$-ray diffraction techniques are employed to measure thermal and residual stresses in the welded joints. The weld pool temperatures are recorded during each pass of the welding process with infrared thermography. The temperatures were measured using the FLIR infrared thermography, with an accuracy of $\pm 0.1 \mathrm{C}$. The thermal imager measures the amount of heat emitted by the surface. The infrared thermography is used for measuring the temperature in the weldment. The base material surface-emission efficiency is necessary for measuring the surface temperature of the joint. In this work, the emissivity was taken equal to $\varepsilon=0.9$. Figure 6 shows how the infrared thermography works.

3.1.2. X-Ray Diffraction. The weld area undergoes a heating and cooling cycle during the welding process. The thermal expansion and contraction of the parent material affect residual stresses and distortions. Figure 7 displays the Bruker D8-Discover ${ }^{\mathrm{TM}}$ diffractometer for measuring residual stresses. Figure 8 shows the $\operatorname{Vantec}^{\mathrm{TM}}$ area locator, and goniometer head is used for microfocus with laser tracking. Table 4 summarizes the measuring parameters.

The residual stresses were calculated by using Bragg's law(equation (6)):

$$
n \lambda=2 d \sin \theta,
$$

where $n$ refers to the order of reflection beam, $d$ is the interplanar lattice spacing, $\lambda$ is the wavelength of the incident wave, and $\theta$ is the scattering angle. In the transverse direction, the residual stresses are measured on the top surface and calculation [22] of the residual stress is carried out by using the following equation:

$$
\sigma_{\phi}=\frac{m}{d_{0}}\left(\frac{E}{1+v}\right)
$$

where $E$ is Young's modulus, $v$ is Poisson's coefficient, $d_{0}$ is the stress-free lattice spacing, and $m$ is the slope of the curve drawn between $d$ (spacing) and $\sin ^{2} \Psi$.

\section{Result and Discussion}

ANSYS (APDL) was used for modelling, meshing, and transient thermal and static structural analysis. The computational welding mechanics technique was applied to reduce the CPU time by solving in a consecutive manner the thermal and the mechanical analysis for each welding pass. Temperatures and residual stresses at nodes were analysed in the transverse direction of the weldments. The details are illustrated in further sections given below.

4.1. Thermal Distribution. The welding cycle time was $40 \mathrm{~s}$ for all the passes. The cooling cycle was maintained for about $1000 \mathrm{~s}$ after the last welding run. Between a welding pass and the other one, an inter-pass temperature of about $250^{\circ} \mathrm{C}$ was maintained to avoid hot cracking. Figure 9 illustrates the numerically assessed temperature map. During the first welding pass, a maximum temperature of $2080^{\circ} \mathrm{C}$ was observed, whereas the second pass induced a maximum temperature equal to $2158^{\circ} \mathrm{C}$ and a minimum temperature of $250^{\circ} \mathrm{C}$ (imposed inter-pass temperature). Finally, the pass -3 produced a maximum temperature of $1707^{\circ} \mathrm{C}$. The maximum temperature was experimentally seen at the weld zone of the real joints. The heat is collected at the weld zone of the joint and extends in the transverse direction, which leads to form the HAZ. A narrow FZ was observed due to the low thermal conductivity of the analysed alloy.

4.2. Thermal Analysis Using Infrared Thermography. Thermal distribution during the welding is displayed in Figures 10(a)-10(c). Line-1 represents the longitudinal and 


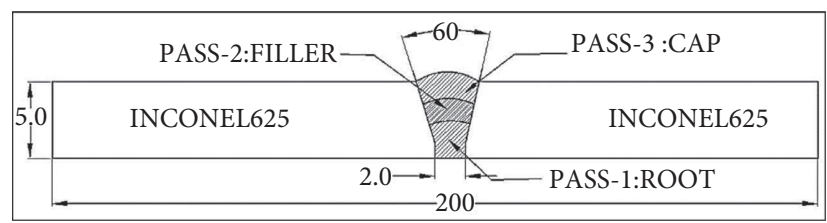

Figure 5: Multi-pass welding process.

TABLe 2: Base plate and filler material chemical properties (wt \%).

\begin{tabular}{lccccccccccccc}
\hline Samples & $\mathrm{Ni}$ & $\mathrm{C}$ & $\mathrm{Mn}$ & $\mathrm{S}$ & $\mathrm{Cu}$ & $\mathrm{Si}$ & $\mathrm{Cr}$ & $\mathrm{P}$ & $\mathrm{Fe}$ & $\mathrm{Al}$ & $\mathrm{Mo}$ & $\mathrm{Ti}$ & $\mathrm{Others}$ \\
\hline $\begin{array}{l}\text { Inconel 625 } \\
\text { Filler wire }\end{array}$ & 58 & 0.1 & 0.5 & 0.015 & 0.5 & 0.5 & $20-23$ & 0.015 & 5 & 0.40 & $8-10$ & 0.1 & - \\
ERNiCrMo-3 & 64 & 0.1 & 0.5 & 0.015 & 0.50 & 0.5 & $22-23$ & 0.015 & 1 & 0.40 & 0.015 & 0.40 & $\mathrm{Nb} 3.6-4.5$, \\
\hline
\end{tabular}

TABle 3: Parent material mechanical properties.

\begin{tabular}{lccc}
\hline Material & Yield strength (YS) $(\mathrm{MPa})$ & Poisson's ratio & Coefficient of thermal expansion \\
\hline Inconel 625 & 254 & 0.28 & $12.3 e^{-6}$ \\
\hline
\end{tabular}

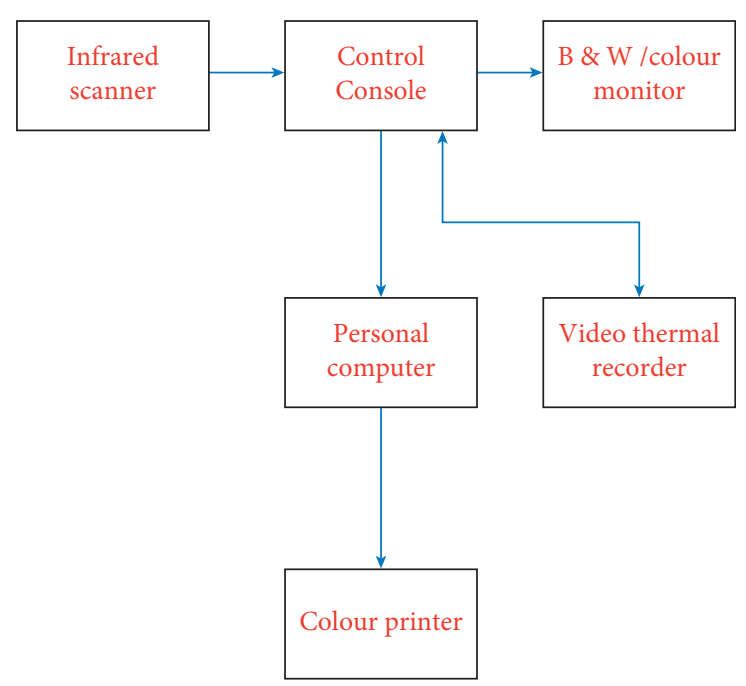

FIGURE 6: Illustration of thermography system.

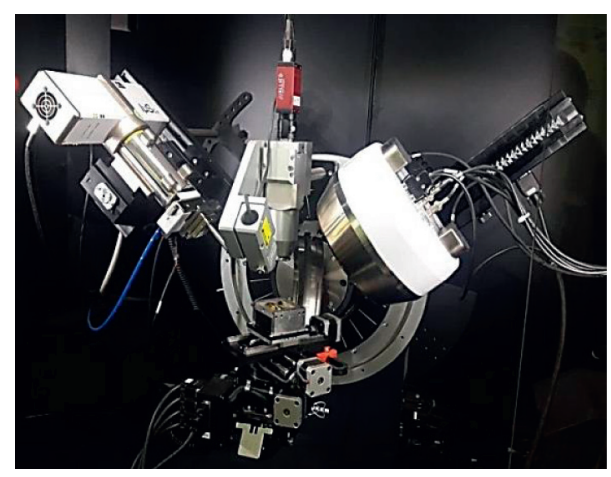

FIgure 7: Bruker X-ray diffraction. 


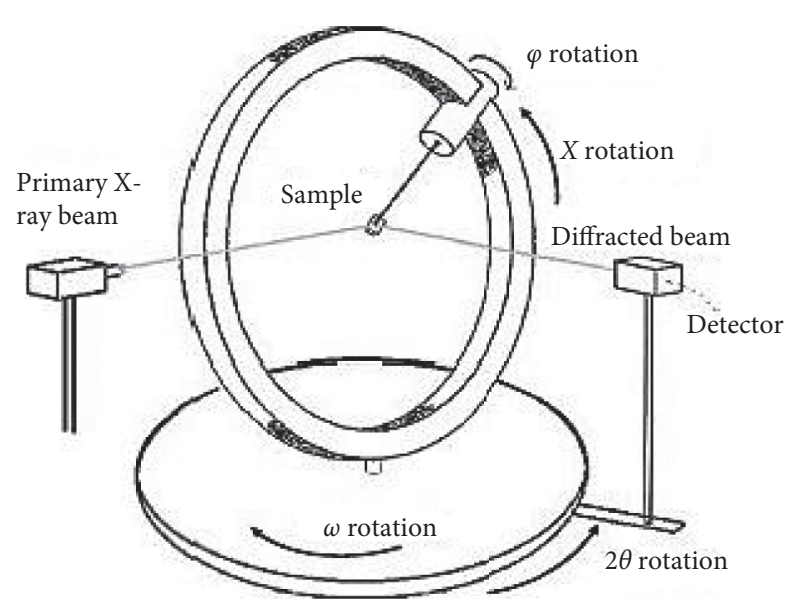

FIGURE 8: Goniometer head with a detector.

TABLE 4: XRD measuring parameters.

\begin{tabular}{lr}
\hline Measurement & Transverse direction \\
\hline Tube & Mn_K-Alpha \\
Bragg angle & $155.0^{\circ}$ \\
Peak location & Gaussian-80\% \\
D-spacing (Angstroms) & 1.0771016 \\
Wavelength & 2.103 \\
\hline
\end{tabular}

line- 2 for the transverse direction of the weld plate, respectively, as shown in Figure 10(a). The temperatures can be recorded at any point of time, and the current thermography results are reported at the welding zone in the longitudinal and transverse directions at the instance of time. Figure 10(a) shows the temperature distribution ranges from $500^{\circ} \mathrm{C}$ to $1779.5^{\circ} \mathrm{C}$ in the transverse direction and from $500^{\circ} \mathrm{C}$ to $1580^{\circ} \mathrm{C}$ in the longitudinal direction. During the second welding pass, the measured maximum temperatures were $1838^{\circ} \mathrm{C}$ and $1867^{\circ} \mathrm{C}$ in the transverse and longitudinal directions, respectively (Figure 10(b)). The temperature distribution as shown in Figure 10(b) was waving up and down because the material was filled in the root gap, filler, and cap (Figure 5). The maximum interpass temperature $250^{\circ} \mathrm{C}$ was maintained in between the passes. Figure 10 (c) shows the final welding pass; the maximum temperatures were reported to be $1325^{\circ} \mathrm{C}$ and $1878^{\circ} \mathrm{C}$ for the longitudinal and transverse directions, respectively. The measured torch temperature value was $1000^{\circ} \mathrm{C}$.

The experimental and numerical peak temperature values at each welding pass are compared in Figure 11. It is observed that the thermal results of FEA simulation slightly differ from experimental ones. This phenomenon is due to the fixed time assumption for all the welding passes, i.e., $40 \mathrm{~s}$.

The FZ geometry and dimensions are shown in the macrograph of Figure 12. It was wide, with $11.38 \mathrm{~mm}$ on the top of the weld, $5.69 \mathrm{~mm}$ in the midsection ( $2.5 \mathrm{~mm}$ thick), and $6.7 \mathrm{~mm}$ on the bottom of the plate. Metallographic examinations revealed a sound weld without defect and a fully penetrated bead. The filler wire is mixed well with parent material, and homogeneous joint was formed.
4.3. Residual Stresses. The residual stress developed across the welding direction of various weldments using simulation is reported here. The residual stress distribution is shown in Figure 13. After pass-1, the weldment experiences compressive stress of $-200 \mathrm{MPa}$ at fusion zone and $-120 \mathrm{MPa}$ at the end of the plate as shown in Figures 13(a). Figure 13(b) shows the residual stresses induced by pass-2. They range from $-110 \mathrm{MPa}$ in fusion zone to $120 \mathrm{MPa}$ close to the HAZ. The parent metal is stress free. After pass-3, the total plate experiences tensile stresses, with a value of $178 \mathrm{MPa}$ in the $\mathrm{FZ}$ and $18 \mathrm{MPa}$ far from it (at the end of the plate) (Figure 13(c)).

The measured tensile residual stress distribution was observed at weld zone and compressive stress in remaining zones. This is due to the expansion of the material during welding and high temperatures at the fusion zone; however, this expansion is retarded by the neighbouring base metal region. The material experiences contraction while cooling to maintain the plate's original dimension, which generates plastic deformation. At HAZ, it undergoes high-stress concentration to maintain the equilibrium between shrinkage action of the base plate and the solidification of the molten weld pool. It is determined that balanced stress distribution in the weldment is due to uniform thermal conductivity along the plates. Figure 14 shows the comparison between experimentally measured and numerically predicted residual stresses analysed for a welded joint. It is observed that the material experiences tensile stresses near the weld bead. The maximum experimental and numerical tensile stress was observed to be $200 \mathrm{MPa}$ and $178 \mathrm{MPa}$, respectively. Further, it was verified that the stresses were not 


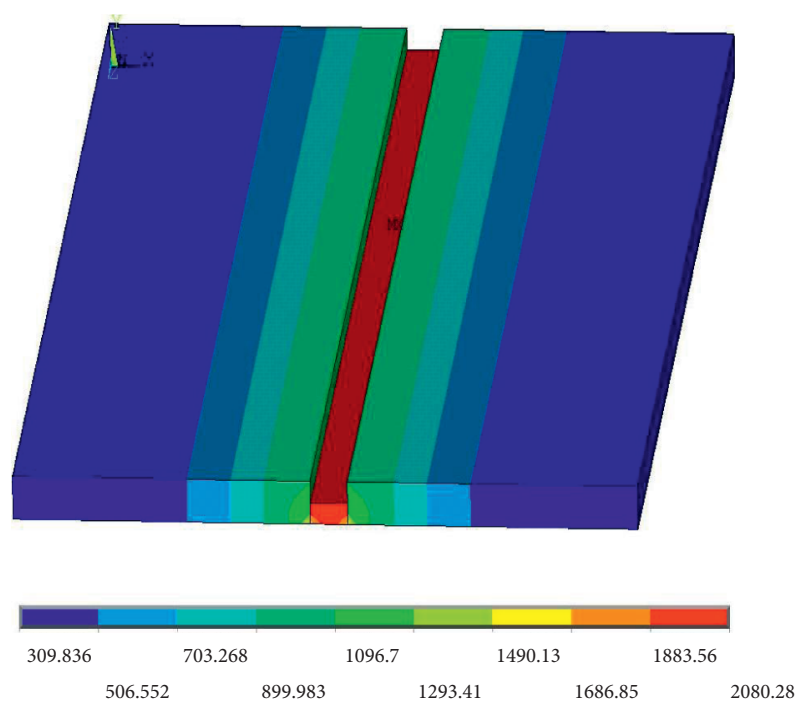

(a)

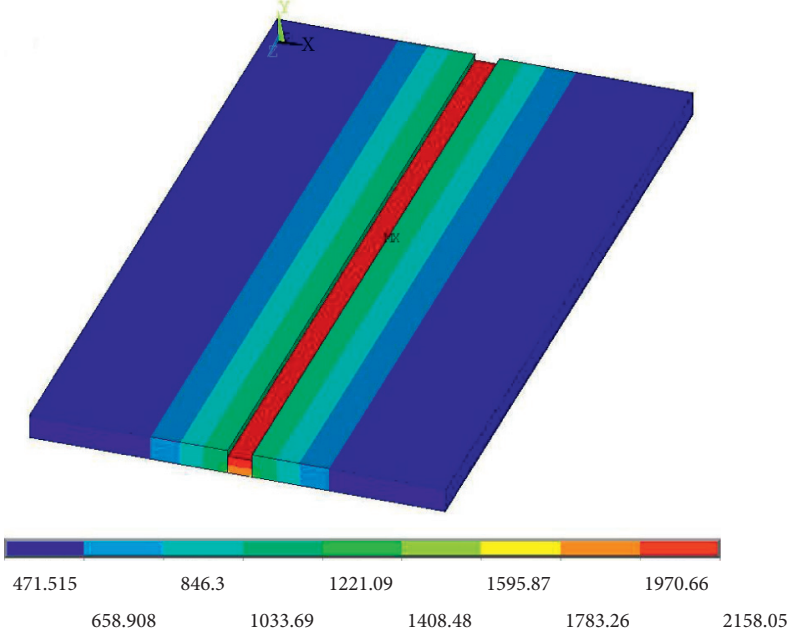

(b)

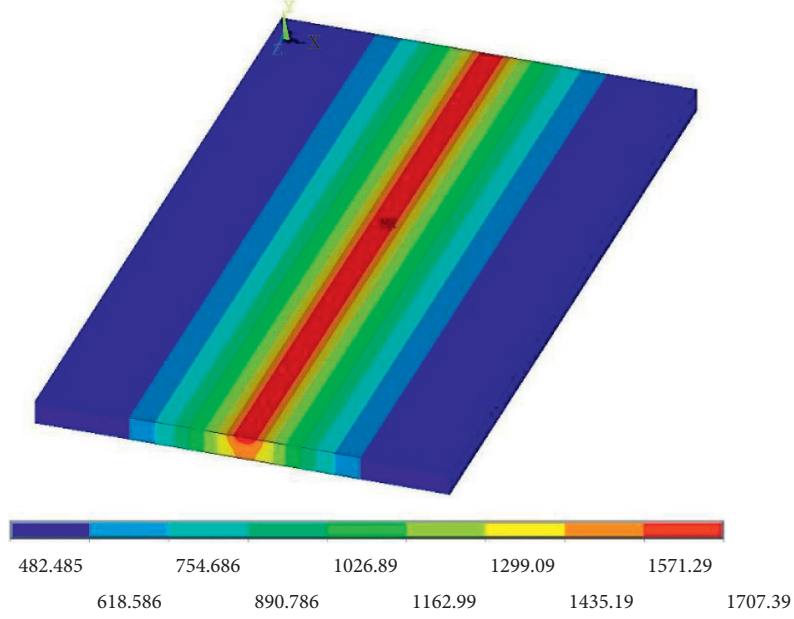

(c)

Figure 9: Distribution of temperatures in the weldment. (a) Weld pass-1. (b) Weld pass-2. (c) Weld pass-3.
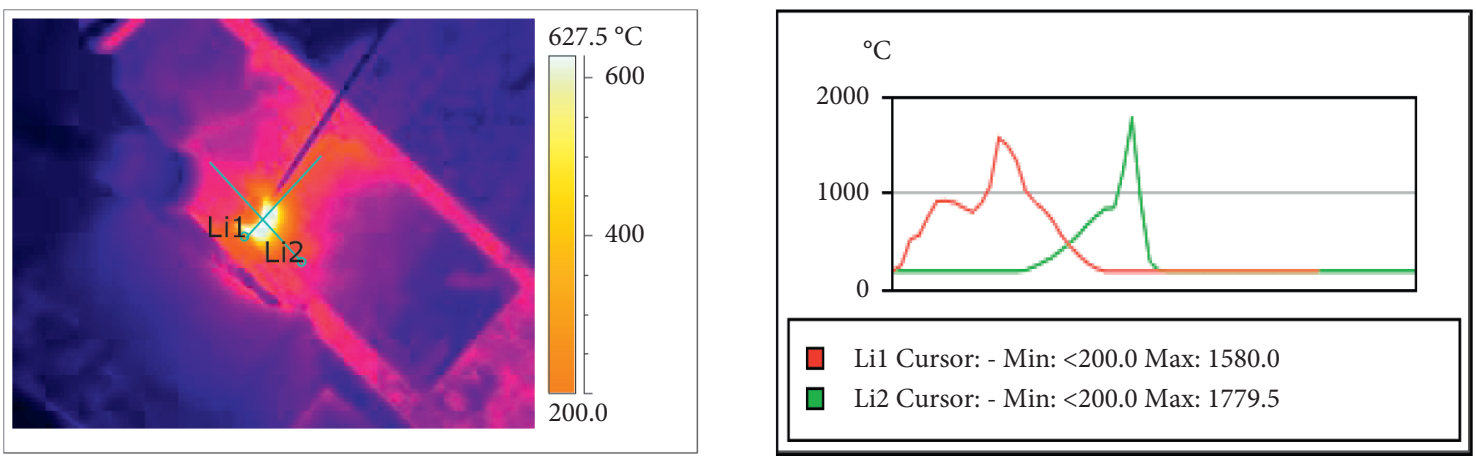

(a)

FIgURe 10: Continued. 

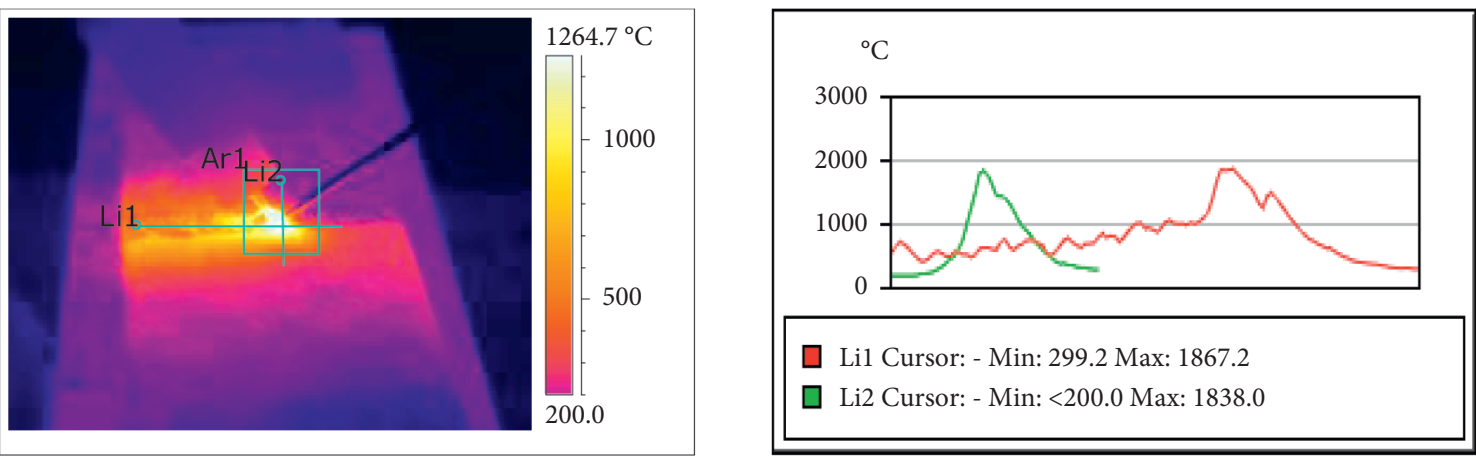

(b)
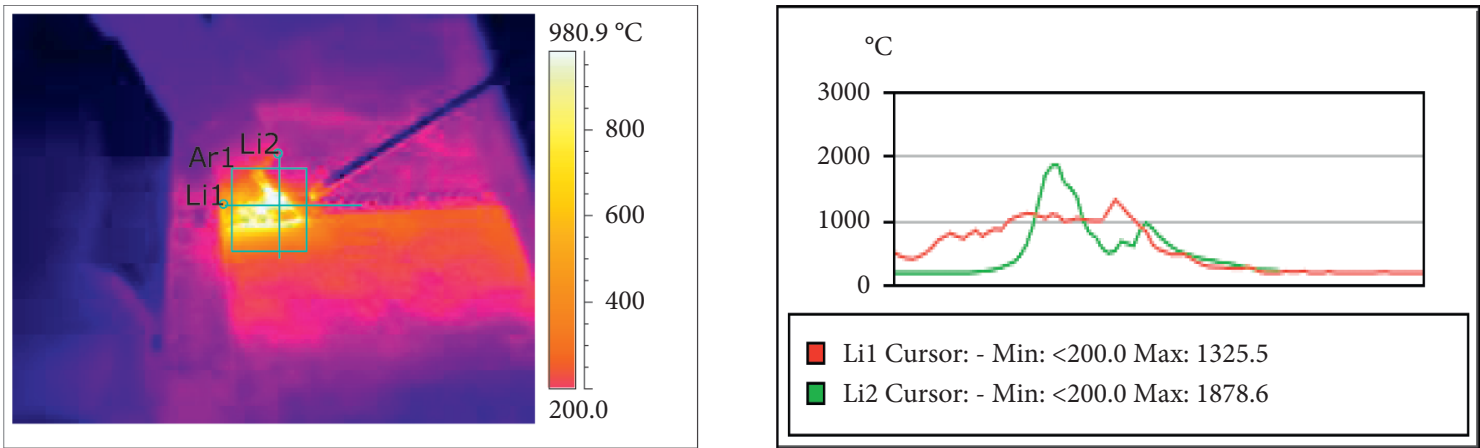

(c)

Figure 10: Infrared thermography pass-wise analysis during the process. (a) Pass-1 IN625 to IN625. (b) Pass-2 IN625 to IN625. (c) Pass-3 IN625 to IN625.

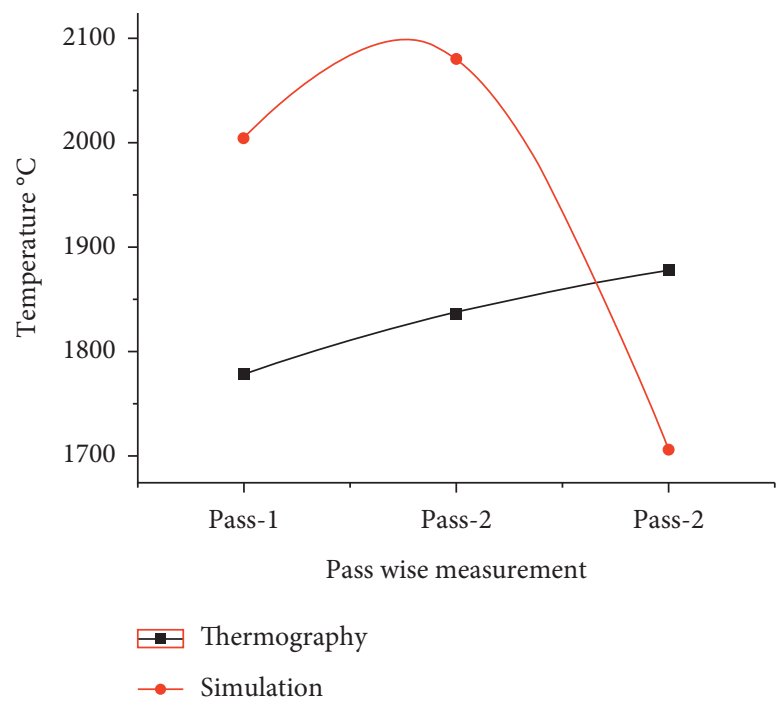

Figure 11: Comparison of thermal distribution.

self-balanced in the structure. Temperature measurements were collected pass by pass from the analysis, and the agreement was $9.08 \%$. The agreement between the measured and analysed residual stress was $11 \%$. Due to the influence of heat input in small areas during establishing the weld joint, the regions next to the weld line undergo severe thermal cycles, resulting in an increase in residual stresses. The result will be a reduction in the structure's life. The same was seen in the current investigation for welding simulation results, with an increase in the error percent of residual stresses. Studies have shown that the maximum residual stress occurs due to the assumption of a constant welding duration in the simulation. In the experiment, the welding duration is changed depending on the weld machine's duty cycle and 


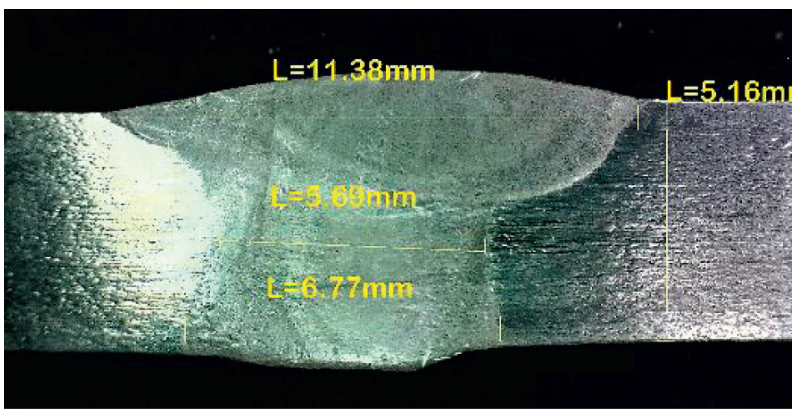

Figure 12: Weld bead geometry of the final weldment.
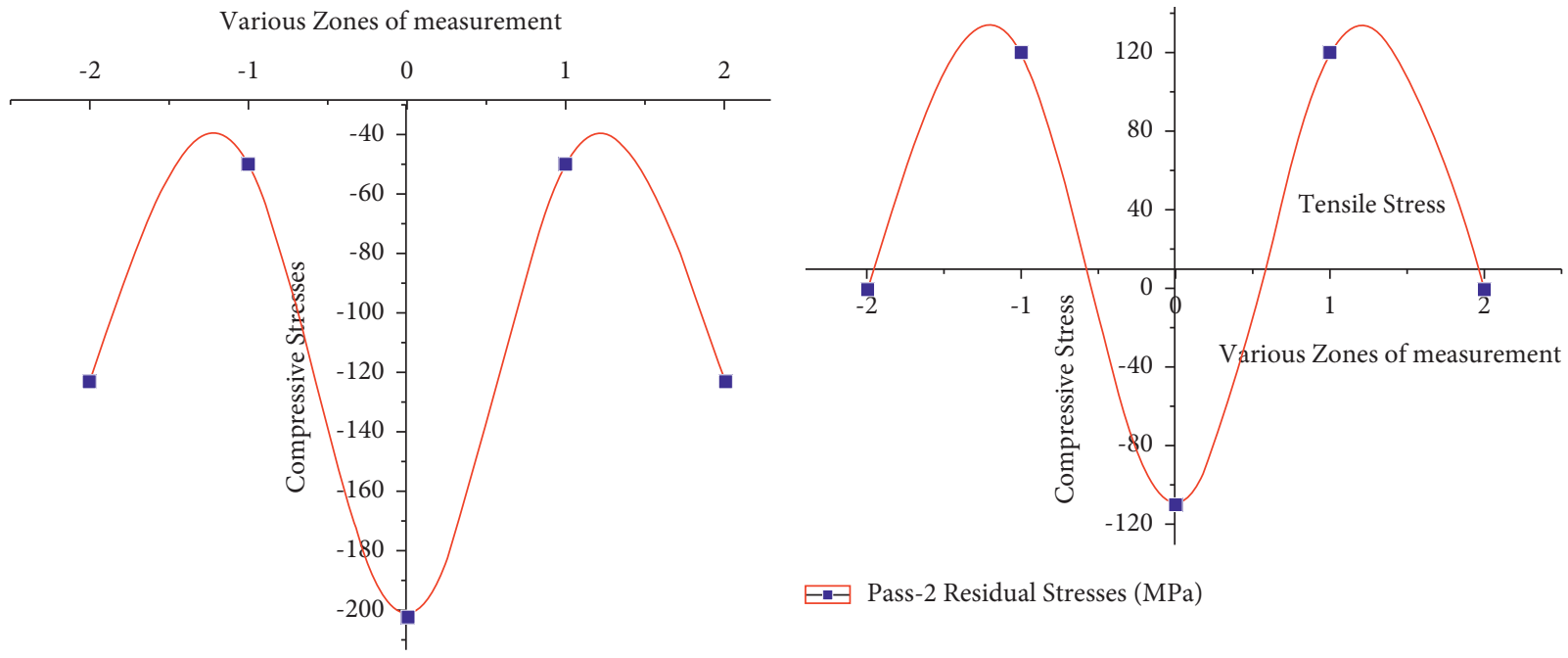

$\square$ Pass-2 Residual Stresses (MPa)

$-\square$ Pass-1 Residual Stresses (MPa)

(a)

(b)

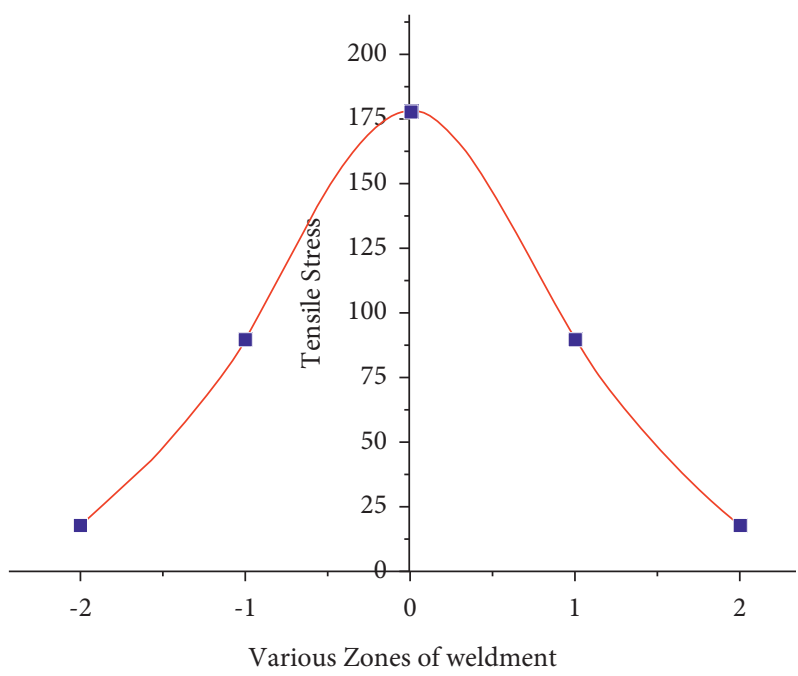

$\square$ Pass-3 Residual Stress (MPa)

(c)

Figure 13: Distribution of residual stress using FEA. (a) Weld pass-1. (b) Weld pass-2. (c) Weld pass-3. 


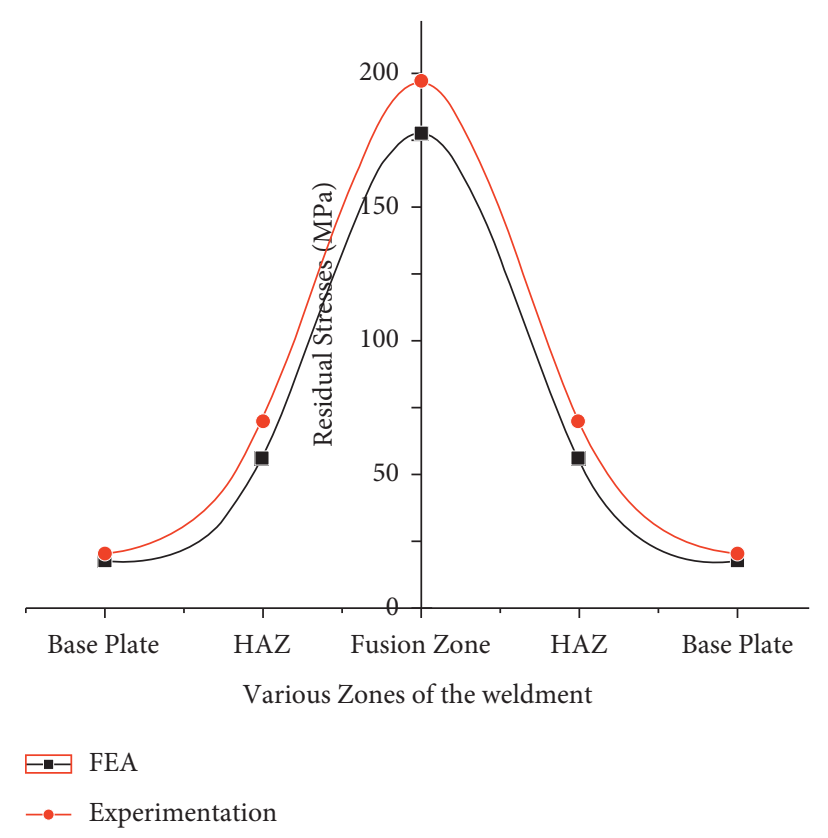

FIgURE 14: Comparison of residual stresses.

when the filler wire melts and solidifies. Additionally, in Lostado et al.'s research [15], they noted that the welded joints can be expanded greatly if nonlinearities are present. This influence results in the dropping of structural integrity.

\section{Conclusions}

Computational welding mechanics used ANSYS to predict residual stresses and temperature distribution arising from the Inconel 625 multi-pass GTAW process. A double ellipsoidal volumetric heat source model with boundary conditions was used for the thermal analysis.

(i) The multi-pass welding process was established successfully for Inconel 625 by the GTAW process for $5 \mathrm{~mm}$ thick plate free from flaws and defects.

(ii) The hot cracking flaws were eliminated by including inter-pass temperatures between the second and third passes. The results are in good agreement with the predicted thermal and mechanical boundary conditions.

(iii) The residual stresses generated were within the yield limits of the parent material.

(iv) The factor of safety was 1.27 for experimentation and 1.42 for simulation of the Inconel 625 welding process.

(v) Temperature measurements were collected pass by pass from the analysis, and the agreement was $9.08 \%$. The agreement between the measured and analysed residual stress was $11 \%$.

\section{Data Availability}

The data used to support the findings of this study are included within the article.

\section{Conflicts of Interest}

The authors declare that they have no conflicts of interest.

\section{References}

[1] A. Kermanpur, M. Shamanian, and V. E. Yeganeh, "Threedimensional thermal simulation and experimental investigation of GTAW circumferentially butt-welded Incoloy 800 pipes," Journal of Materials Processing Technology, vol. 199, no. 3, pp. 295-303, 2008.

[2] Y.. Balram and G. Rajyalakshmi, "Thermal stress analysis of similar and dissimilar welded joints," U.P.B. Sci. Bull., Series D, vol. 80, no. 4, pp. 1-7, 2018.

[3] P. K. Korrapati, V. K. Avasarala, M. Bhushan, K. D. Ramkumar, N. N. Arivazhagan, and S. Narayanan, "Assessment of mechanical properties of PCGTA weldments of Inconel 625,” Procedia Engineering, vol. 75, pp. 9-13, 2014.

[4] M. Perić, Z. Tonković, A. Rodić et al., "Numerical analysis and experimental investigation of welding residual stresses and distortions in a T-joint fillet weld," Materials \& Design, vol. 53, pp. 1052-1063, 2014.

[5] H. Vemanaboina, G. Edison, and S. Akella, "Effect of residual stresses of GTA welding for dissimilar materials," Materials Research, vol. 21, no. 4, pp. 1-7, 2018.

[6] H. Vemanaboina, G. Edison, and S. Akella, "Weld bead temperature and residual stresses evaluations in multipass dissimilar INCONEL625 and SS316L by GTAW using IR thermography and x-ray diffraction techniques," Materials Research Express, vol. 6, no. 9, Article ID 0965a9, 2019.

[7] P. Ferro, "Molten pool in welding processes: phenomenological vs fluid-dynamic numerical simulation approach," Materials Science Forum, vol. 884, pp. 26-40, 2017.

[8] H. Vemanaboina, G. Edison, S. Akella, and R. K. Buddu, "Thermal analysis simulation for laser butt welding of Inconel625 using FEA," International Journal of Engineering \& Technology, vol. 7, no. 4, pp. 85-89, 2018. 
[9] R. Keivani, M. Jahazi, T. Pham, A. R. Khodabandeh, and M. R. Afshar, "Predicting residual stresses and distortion during multisequence welding of large size structures using FEM," International Journal Of Advanced Manufacturing Technology, vol. 73, no. 4, pp. 409-419, 2014.

[10] A. G. Kamble and R. V. Rao, "Effects of process parameters and thermo-mechanical simulation of GMAW process for welding of $3 \mathrm{Cr} 12$ steel," Advances in Materials and Processing Technologies, vol. 2, no. 3, pp. 377-400, 2016.

[11] M. J. Attarha and I. Sattari-Far, "Study on welding temperature distribution in thin welded plates through experimental measurements and finite element simulation," Journal of Materials Processing Technology, vol. 211, no. 4, pp. 688-694, 2011.

[12] A. Capriccioli and P. Frosi, "Multipurpose ANSYS FE procedure for welding processes simulation," Fusion Engineering and Design, vol. 84, no. 2-6, pp. 546-553, Jun. 2009.

[13] R. Lostado, R. F. Martinez, B. J. Mac Donald, and P. M. Villanueva, "Combining soft computing techniques and the finite element method to design and optimize complex welded products," Integrated Computer-Aided Engineering, vol. 22, no. 2, pp. 153-170, 2015.

[14] R. Lostado Lorza, R. Escribano García, R. Fernandez Martinez, and M. Martínez Calvo, "Using genetic algorithms with multi-objective optimization to adjust finite element models of welded joints," Metals, vol. 8, no. 4, p. 230, 2018.

[15] R. Lostado Lorza, M. Corral Bobadilla, M. Martínez Calvo, and P. Villanueva Roldán, "Residual stresses with time-independent cyclic plasticity in finite element analysis of welded joints," Metals, vol. 7, no. 4, p. 136, 2017.

[16] H. Vemanaboina, S. Akella, and R. K. Buddu, "Welding process simulation model for temperature and residual stress analysis," Procedia Materials Science, vol. 6, pp. 1539-1546, 2014.

[17] J. Goldak, A. Chakravarti, and M. Bibby, "A new finite element model for welding heat sources," Metallurgical Transactions B, vol. 15, no. 2, pp. 299-305, 1984.

[18] D. Deng and H. Murakawa, "Prediction of welding residual stress in multi-pass butt-welded modified 9Cr-1Mo steel pipe considering phase transformation effects," Computational Materials Science, vol. 37, no. 3, pp. 209-219, 2006.

[19] D. Deng and S. Kiyoshima, "Numerical simulation of welding temperature field, residual stress and deformation induced by electro slag welding," Computational Materials Science, vol. 62, pp. 23-34, 2012.

[20] "The importance of interpass temperature welding innovation," vol. 15, no. 1, 1998.

[21] H. Vemanaboina, G. Guruvaiah Naidu, D. Satya Abhinav, N. Krishna, and D. Ramachandra Reddy, "Evaluation of residual stress in multipass dissimilar butt joints using X-ray diffraction," Materials Today: Proceedings, vol. 19, pp. 283$288,2019$.

[22] A. Osman, Residual Stress Measurement Using X-ray Diffraction, Texas A and M University, College Station, TX, USA, 2004. 